\title{
The Exploration of Transparency on Efficiency Among Non-profit Organizations (NPO) in China
}

\author{
Quanren Jiang, Jinghua Zhang*, Lin Yue \\ School of Business \\ Macau University of Science and Technology \\ Macau, China \\ 1609853fbf20006@student.must.edu.mo,jhuzhang@must.edu.mo*,lyue@must.edu.mo
}

\begin{abstract}
This study examines if higher level of transparency is associated with higher level of efficiency with the efficiency among NPOs measured by the percentage of the donation from public used for charity program purposes or for the mission of an NPO in China. Using 14,183 observations from the year of 2010 to 2015 , we utilized a pooled ordinary least square model (OLS), a fixed effect model (FE) and a dynamic panel model with a firstdifferenced generalized method of moments estimation (GMM). The results showed that NPOs with higher level of transparency are associated with higher level of efficiency. Our findings have valuable policy implication for NPO regulation and management.
\end{abstract}

Keywords-Efficiency; Transparency; Donation dependence; Government funding; Non-profit organizations

\section{INTRODUCTION}

Despite a fast growth of NPOs in China during the recent years, many financial scandals are reported, which have been weakening the dignity of charitable causes and diminishing the accountability of nonprofits [1]. Under such circumstances, Transparency plays a significant role in revealing the scandals, which also shows the trend of marketization. Additionally, marketization is enhancing the speed of charitable field development. Subsequently, an increasing number of open, shared and transparent platforms are born out in the era of information society, which facilitates the public to be closer to the fact of Efficiency within a non-profit organization [2]. To address this research concern, this paper aims to explore the research question: Is higher level of transparency associated with higher level of efficiency with the efficiency among NPOs?

In this paper, we mainly focus on NPOs as they are leading the development of philanthropic sector in China [3]. According to the existing literature, the information disclosure content and related laws and regulations of NPOs are well discussed in the field of NPOs compared to other types of Chinese philanthropic sectors [4].

Drawing from the literature, three main theories are often applied and adopted to conduct studies in chartable field, namely asymmetric information theory, resource dependence theory and trade-off theory. In order to estimate the indicators derived from theories, we construct three dynamic econometric models with three dynamic methods, namely, pooled OLS, FE and GMM are applied in this study to test the relationship between non-profit organizations' transparency and their efficiency, which are overlooked in the prior studies. In the study, the efficiency among NPOs are measured by the percentage of the donation from public used for charity program purposes or for the missions of an organization in China in the light of The Charity Law of the People's Republic of China [5].

According to asymmetric information theory, the frequent sluggishness and misconducts, namely inefficiency, are basically due to the asymmetric information among the donors, trustee and beneficiaries [6]. Hence, to what extent of transparency affects efficiency become the primary point that draws our attention.

Besides, according to resource dependence theory, few organizations could bring out enough diverse resources only by themselves. More importantly, we explore the impact to efficiency from the external resources perspective as it is highly suggested by literatures [7]. In this paper, we highlight two factors, donation dependence and government funding. First, donations are the vital resources to the survival for a great deal of nonprofit organizations [8]. Secondly, China NPOs were top-down created by the government in 1980s, thus, even nowadays a big portion of funds for NPOs is from government financial subsidies [9].

In addition, learned from the trade-off theory, if managers in non-profit organizations target the long-term efficient indicators, or the efficient indicators with a mean-reverting nature itself, we consider the function of transparency will suffer in the potential partial-adjustment process of efficiency, due to the adjustment cost, that typical legal persons can only approach the portion of the gap between its actual and its preference ratios each year. Besides, it may also suffer from the bound nature of efficient indicators, if any, that a NPO with a relatively high efficiency may have nowhere to go but down, and vice versa [10].

From our empirical result, NPOs with higher level of transparency are associated with higher level of efficiency, so we highly suggest the public should place transparency high on the agenda of improving efficiency in Chinese charitable field. Compared with transparency, either the indicator of donation dependence or the indicator of government funding makes much less significant impact on NPOs' efficiency. Taking this argument one step further, since we observe that neither do non-profit organizations have targeted long-run efficiency ratios nor the efficiency contains a mean-reverting nature, the 
improvement of transparency would indeed result in a better efficiency. What's more, there exists some significant unknown natures of China NPOs in efficiency that researchers can keep working on them to guide us, to nearly $40 \%$ extent, to set up an inborn efficient non-profit organization since those natures are unchangeable over time.

\section{RESEARCH METHOD}

This study adopts the China Foundation Transparency Index (FTI) to measure the transparency of the organizations. FTI is constructed by China NPOs Center and is regarded as among the best indicators for transparency in China. FTI is constructed as the sum of 4 categories including 41 subindexes [11].

In our econometric models, a pooled OLS method is applied to estimate the dynamic model (1) with the first-order lag of the efficient indicator [12], which is given by

$$
\begin{aligned}
\text { Chari }_{i, t}=\alpha+ & \beta_{1} \text { L.Chari }_{i, t}+\beta_{2} \text { Transp }_{i, t}+\beta_{3} \text { Donat }_{i, t}+ \\
& \beta_{4} \text { Gover }_{i, t}+\beta_{5} \text { Ln_totas }_{i, t}+\beta_{6} \text { Dum_priv }_{i, t}+ \\
& \beta_{7} \text { Dum_loca }_{i, t}+\beta_{8} \text { Dum_matu }_{i, t}+ \\
& \beta_{9} \text { Dum_youn }_{i, t}+\mu_{t}+\varepsilon_{i, t}
\end{aligned}
$$

Where $i$ indicates each firm and $t$ indexes the time period. Chari $_{i, t}$ stands for the ratio of expenditure for charity activities over total expenditure. L.Chari $i_{i, t}$ represents the first-lagged term of Chari $_{i, t}$. Transp $_{i, t}$ is the extent of transparency, measured by the China NPOs Transparency Index. Donat $t_{i, t}$ is the degree that a foundation relies on its donations, measured by the ratio of donation revenue over total revenue. Gover $_{i, t}$ is the degree that a foundation relies on government funding, measured by the ratio of government funds over total revenue. $L n \_$totas $_{i, t}$ is the size of a foundation measured by natural log of its total assets. $\varepsilon$ is an error term. $\mu_{t}$ is the time effect. Dum_priv $v_{i, t}$ is the type of a foundation, which equals " 1 " if a foundation is a private one and " 0 " if a foundation is a public one. Dum_loca $a_{i, t}$ is the scope of a foundation, which equals " 1 ", if a foundation is a local one and " 0 " if a foundation is a national one. Dum_matu $u_{i, t}$ equals " 1 " if the date of a foundation's establishment is in the range from 1 st to $33 \mathrm{nd}$ percentile of the timeline and " 0 " if otherwise. Likewise, Dum_youn $_{i, t}$ equals " 1 " if the date of a foundation's establishment is in the range from 67 th to the very end of the timeline and " 0 " if otherwise.

Then, the FE method is applied to estimate dynamic model (2) with the first-order lag of the efficient indicator [10], which is given by

$$
\begin{array}{r}
\text { Chari }_{i, t}=\mu_{i}+\beta_{1} \text { L.Chari }_{i, t}+\beta_{2} \text { Transp }_{i, t}+\beta_{3} \text { Donat }_{i, t}+ \\
\beta_{4} \text { Gover }_{i, t}+\beta_{5} \text { Ln_totas }_{i, t}+\mu_{t}+\varepsilon_{i, t}
\end{array}
$$

Where $\mu_{i}$ implies an unobserved time-invariant foundationspecific effect, which consists of a set of dummy variables that each foundation has one. We notice its unchangeable nature as without subscript, $t$.

The main difference in (1) and (2) is that the dummy variables as Dum_privit, Dum_loca $i_{i, t}$, Dum_matu $u_{i, t}$ and Dum_youn $_{i, t}$ are replaced by an unobserved time-invariant foundation-specific effect, $\mu_{i}$, to see if the foundation-specific feature in (2) contains more stuff other than those 4 factors in (1).

Whereas it is biased upwards of the coefficient estimate that the first-lagged explained variable L.Chari $_{i, t}$ would reveal in (1) and it is biased downwards of the coefficient estimate that L.Chari $_{i, t}$ in (2) [13], these 2 types of bias make up an estimated range that the real coefficient of L.Chari $_{i, t}$ should be exactly within.

To obtain the unbiased estimate of L.Chari $i_{i, t}$, the dynamic panel model using GMM to estimate is given by

$$
\begin{aligned}
\Delta \text { Chari }_{i, t}= & \beta_{1} \Delta \text { L.Chari }_{i, t}+\beta_{2} \Delta \text { Transp }_{i, t}+\beta_{3} \Delta \text { Donat }_{i, t}+ \\
& \beta_{4} \Delta \text { Gover }_{i, t}+\beta_{5} \Delta L \text { L_totas }_{i, t}+\Delta \mu_{t}+\Delta \varepsilon_{i, t}
\end{aligned}
$$

Where we convert (2) to (3), by first-differencing (2) to eliminate the $\mu_{i}$, and spot that the first difference of size of a foundation can be regard as variant slowly variable, namely predetermined variable, as the shock from the error term will impact on its future development. Then Chari $_{i, t-2}$ and Chari $_{i, t-3}$ as well as $L n \_$totas $_{i, t-1}$ and Ln_totas ${ }_{i, t-2}$ are used to instrument for the $\Delta L$.Chari $i_{i, t}$ and $\Delta$ Ln_totas $_{i, t}$ to be immune to the weak instruments of the explained variable. The two-stage least squares and robust estimations are adopted in our dynamic panel model.

In our unreported robustness test, we switch the dependent variable in our model from an efficient one to an inefficient one, namely from Chari $_{i, t}$ to $\operatorname{Admin}_{i, t}$, that is the ratio of expenditure for administrative over total expenditure. More specifically, the total expenditure in a NPO can be divided into three parts: the expenditure for charity activities, the expenditure for administrative and the expenditure for workers' wages and benefits. To avoid the multicollinearity, we drop the expenditure for workers' wages and benefits from our model.

\section{DATA ANALYSIS}

Our database consists of 14,183 samples of China NPOs over a 6-year period from 2010 to 2015. Chari $_{i, t}$ and Donat ${ }_{i, t}$ are censored if they are over 100 to clean the outliers since the ratio they indicate should not be over 100 percent. Statistical software Stata 15.0 was adopted to do the data analysis. The descriptive statistics of NPOs is shown in Table I.

\section{EMPIRICAL RESULTS AND DISCUSSION}

As refer to Table II, we investigate these three dynamic models respectively using the approaches introduced above.

While look closer at the Adjusted R-Square line, the pooled OLS model is much inferior to FE model, indicating it is about $25 \%$ more uncertain factors that the foundation-specific effects $\mu_{i}$ contain in _cons of FE model than just controlling the type, the scope, the age and a simple $\alpha$ in _cons of pooled OLS model. 
TABLE I. Descriptive Statistics of NPOS in Datebase

\begin{tabular}{|l|l|l|l|l|l|}
\hline VarName & Mean & SD & Min & Median & Max \\
\hline Chari & 91.23 & 16.48 & 0.00 & 95.72 & 100.00 \\
\hline Admin & 4.13 & 11.17 & 0.00 & 1.53 & 100.00 \\
\hline Transp & 58.21 & 19.06 & 0.80 & 54.74 & 129.40 \\
\hline Donat & 67.76 & 38.63 & 0.00 & 89.80 & 100.00 \\
\hline Gover & 5.38 & 17.71 & 0.00 & 0.00 & 100.00 \\
\hline Ln_totas & 16.09 & 1.41 & 7.72 & 15.91 & 22.37 \\
\hline Dum_priv & 0.56 & 0.50 & 0.00 & 1.00 & 1.00 \\
\hline Dum_loca & 0.93 & 0.25 & 0.00 & 1.00 & 1.00 \\
\hline Dum_matu & 0.35 & 0.48 & 0.00 & 0.00 & 1.00 \\
\hline Dum_youn & 0.31 & 0.46 & 0.00 & 0.00 & 1.00 \\
\hline
\end{tabular}

TABLE II. EMPIRICAL MODELS OF EFFICIENCY

\begin{tabular}{|c|c|c|c|}
\hline & (1) & (2) & (3) \\
\hline Chari & OLS & FE & GMM \\
\hline \multirow[t]{2}{*}{ L.Chari } & $0.33^{* * *}$ & $-0.05^{* * *}$ & $0.12 * *$ \\
\hline & $(35.86)$ & $(-4.29)$ & $(2.17)$ \\
\hline \multirow[t]{2}{*}{ Transp } & $0.09 * * *$ & $0.17 * * *$ & $0.17 * * *$ \\
\hline & (11.99) & (12.54) & $(4.58)$ \\
\hline \multirow[t]{2}{*}{ Donat } & $0.05^{* * *}$ & $0.04 * * *$ & $0.07 * * *$ \\
\hline & $(14.05)$ & $(7.34)$ & $(4.41)$ \\
\hline \multirow[t]{2}{*}{ Gover } & $0.05 * * *$ & $0.06^{* * *}$ & $0.07 * * *$ \\
\hline & $(6.03)$ & $(4.72)$ & $(2.93)$ \\
\hline \multirow[t]{2}{*}{ Ln_totas } & $0.78^{* * *}$ & 0.42 & $-18.59 * * *$ \\
\hline & $(7.37)$ & $(1.14)$ & $(-4.44)$ \\
\hline \multirow{2}{*}{ Dum_priv } & 0.24 & & \\
\hline & $(0.81)$ & & \\
\hline \multirow[t]{2}{*}{ Dum_loca } & $1.96^{* * *}$ & & \\
\hline & $(3.58)$ & & \\
\hline \multirow[t]{2}{*}{ Dum_matu } & $-1.13 * * *$ & & \\
\hline & $(-3.45)$ & & \\
\hline \multirow[t]{2}{*}{ Dum_youn } & 0.13 & & \\
\hline & $(0.37)$ & & \\
\hline \multirow[t]{2}{*}{ cons } & $38.73 * * *$ & $71.43 * * *$ & $367.71 * * *$ \\
\hline & $(18.55)$ & $(8.15)$ & $(5.22)$ \\
\hline Adj. R-Square & 0.18 & 0.42 & \\
\hline LL & -41101.63 & -37490.23 & \\
\hline LR $\chi^{\wedge} 2(d)$ & \multicolumn{2}{|c|}{$7222.81(3109)$} & \\
\hline LR P Value & \multicolumn{2}{|l|}{0.000} & \\
\hline $\mathrm{AR}(2) \mathrm{Z}$-statistic & & & -1.46 \\
\hline AR(2) P Value & & & 0.14 \\
\hline Sargan $\chi^{\wedge} 2(\mathrm{~d})$ & & & $16.93(14)$ \\
\hline Sargan P Value & & & 0.26 \\
\hline
\end{tabular}

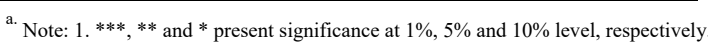

2. $\mathrm{t}$-values are in parentheses.
In line with Adjusted R-Square, the maximum likelihood value (LL) increases shows the model fitting is better in FE model than pooled OLS model, and the $\mathrm{P}$ value of the likelihood-ratio (LR) test implies a significant improvement in model fitting. Therefore, we argue that the unobserved timeinvariant foundation-specific effect, $\mu_{i}$ should be considered more than generally appeal to type, scope and age as loads of previous literatures did [14].

Furthermore, following evidences jointly ensure a reasonable setting of our dynamic panel model against the endogenous problem. Firstly, the coefficient estimate of L.Chari $_{i, t}$ in our dynamic panel model is 0.12 at the $5 \%$ significance level, between the one of pooled OLS model and FE model as is expected, that is within the range from 0.33 to 0.05 , either at the $1 \%$ significance level. Plus, the second-order serial autocorrelation test $\mathrm{AR}(2)$, and the Sargan test for overidentifying restrictions both don't reject their null hypotheses as no autocorrelation in first-differenced errors and overidentifying restrictions are valid. Hence model (3) avoids the endogenous problem of dynamic panel model that makes the estimates are often inconsistent got by a pooled OLS estimation and a FE estimation, so that reaches the top as its unbiased, consistent and efficient coefficient estimates.

To shed more light on Table II, we are quite confident to confirm the causal effect of transparency on efficiency in the case of China NPOs as the estimated coefficient for Transp $_{i, t}$ in all three models remains the same significant signal and obtain a pretty stable estimate at the $1 \%$ significance level. Although Donat $_{i, t}$ and Gover $_{i, t}$ show similar patterns, as estimated coefficients of them are all very significant, they make much less impacts on Chari $_{i, t}$ than Transp $p_{i, t}$, whose absolute value of the coefficient is over the sum of which of Donat ${ }_{i, t}$ and Gover ${ }_{i, t}$. To be more specifically, $1 \%$ improvement is made in Transp $p_{i, t}$, Donat $_{i, t}$ and Gover $_{i, t}$ will result in $0.17 \%, 0.07 \%$ and $0.07 \%$ enhancement in efficiency accordingly. One thing should be noticed that we control Dum_priv ${ }_{i, t}$,Dum_loca ${ }_{i, t}$, Dum_matu $u_{i, t}$ and Dum_youn ${ }_{i, t}$ only to gauge and emphasize the unobserved time-invariant foundation-specific effect $\mu_{i}$ instead of caring about the their effects since their estimates may suffer from the omitted-variable bias.

Then we also notice that, as mentioned in research mehod section, the credible and unbiased estimated coefficient of L.Chari $_{i, t}$ in (3), that is the dynamic panel model using GMM, is significant positive 0.12 , so a sustainable development relationship is discovered between the current degree efficiency and its forward period, which can be regarded as the further improvement of transparency would indeed lead to a better efficiency. Because if the negative estimate of L.Chari $_{i, t}$ is the case, that either shows non-profit organizations have targeted a long-run efficiency ratio or the Chari $i_{i, t}$ itself contains a meanreverting nature, any efforts trying to achieve a constant higher efficiency can be useless.

However, one thing unexpected, the coefficient estimate of Ln_totas $_{i, t}$ displays -18.589 at the $1 \%$ significance level. In spite of inconsistent estimates obtained in different model, a similar result yielded by our unreported robustness test. It is certain that the indicator of size, Ln_totas ${ }_{i, t}$, may have a 
significant negative association with the expenditure but not efficiency that could be explored further.

Next, we reveal more details about our unreported robustness test. To begin with, we switch the dependent variable in our model from Chari $_{i, t}$ to Admin $_{i, t}$. Holding everything else constant, we observe that a lower extent of either transparency or donation dependence or government funding would result in a higher level of inefficiency. The Transp $_{i, t}$ still remains as the major cause of $A d m i n i, t$. So does the result of $\operatorname{LAdmin}_{i, t}$, still displaying that without the existence of a predetermined efficient ratio or a bound nature, the inefficiency will keep fading away as the constant improvement of transparency. Moreover, we also have developed a diversity of approaches to test for the better fitting among our econometric models before drawing our conclusion. For instance, we conducted the test for both efficiency and inefficiency indicators with 2 static models without the firstlagged explained variable L.Chari $i_{i, t}$, consisting of pooled ordinary least square model and FE model in addition. Although the Adjusted R-Square as well as the likelihood-ratio test (LR) tell us the dynamic part always fits our database better than the static part, we have exactly the same


dynamic models. Then we estimated both the static and the dynamic FE model by subtracting the foundation-specific effect out in advance so as to make the F-test and the DurbinWu-Hausman test, and reach similar outcomes that the dynamic panel model with GMM estimation, that we performed in this paper, fits our database the best, so that the results on Table II are good to be believed. All these robustness tests results are available upon request.

\section{CONCLUSION AND SUGGESTION}

From the perspective of the academics, first and foremost, NPOs position themselves as more transparent will achieve a higher level of efficiency, which is found as the most essential reason of the different efficiency among Chinese non-profit organizations. In other words, our studies claim that NPOs with higher level of transparency are associated with higher level of efficiency.

Besides, either the donation dependence or the government funding of a foundation have much less positive impact on efficiency compared with transparency, while the size of NPOs can hardly be regard as a good indicator for efficiency.

Meanwhile, a time-invariant foundation-specific effect remains nearly $25 \%$ of uncertainty of the efficiency change instead of controlling for type, scope and age. Therefore some unknown natures other than those factors that remarkable affect efficiency that we can keep working on them.

Last but not least, by referring to the first-lagged term of efficiency indicator, no evidence for non-profit organizations have made long-run target of efficiency or efficiency indicator contains a mean-reverting nature. Thus the improvement of transparency would indeed result in a better efficiency.

From the perspective of the society, we highly suggest the public should place transparency high on the agenda of improving efficiency in Chinese charitable field, because the improvement of transparency can be consider as an useful management instrument to boost the fair use of NPO resources for charitable purposes and therefore the higher level of efficiency. Meanwhile, as we proved that an unobserved timeinvariant foundation-specific effect do exist, that is, some NPOs may have a talent in efficiency due to some unknown factors that can't be changed easily over time, say, their type, location, chairman personality or something like that. Thereby, future researchers can follow this path and track out those significant unknown natures to guide us, to nearly $40 \%$ extent, to set up an inborn efficient non-profit organization.

However, it is hard to believe that the larger size brings about the recession of expenditure in both efficient charitable grants and inefficient administrative costs. Nonetheless, a reasonable explanation is raised up as the expenditure may go to wages and benefits to their workers deserve further investigations.

\section{REFERENCES}

[1] L.L. Liu, "Is Internal Governance Of Non-Profit Organization In China Effective: Based on The Data of Foundations," China Economic Studies, vol. 2015(2), pp. 98-108, 2015.

[2] M. Wang, "Chinese public charity: Development, reform and trend," The People's Congress of China, vol. 2016(7), pp. 40-44, 2016.

[3] J.E. Mosley and J. Galaskiewicz, "The relationship between philanthropic foundation funding and state-level policy in the era of welfare reform," Nonprofit and Voluntary Sector Quarterly, vol. 44(6), pp. 1225-1254, 2015.

[4] J. Hou and X. Zhuang, "Do donors care about the operational efficiency of nonprofits?-Empirical evidence from top 500 Chinese nonprofit foundations," Journal of China University of Geosciences (Social Sciences Edition), vol. 16(3), pp. 115-126, 2016.

[5] The Charity Law of the People's Republic of China : Chapter 2 charitable organizations, Available at http://www.npc.gov.cn/npc/lfzt/rlyw/2015-10/31/content_1949145.htm, last accessed on May 23th, 2018.

[6] B. Shui, "The legal path of foundation governance-Why does the regulation on foundation administration suffer from "zero application"?", Science of Law (Journal of Northwest University of Political Science and Law), vol. 2010(6), pp. 125-136, 2010.

[7] A.M. Eikenberry and J.D. Kluver, "The marketization of the nonprofit sector: Civil society at risk?" Public Administration Review, vol. 64(2), pp. 132-140, 2004.

[8] W. Elbers and B. Arts, "Keeping body and soul together: Southern NGOs' strategic responses to donor constraints," International Review of Administrative Sciences, vol. 77(4), pp. 713-732, 2011

[9] D. Ma and W.L. Parish, "Tocquevillian moments: Charitable contributions by chinese private entrepreneurs," Social Forces, vol. 85(2), pp. 943-964, 2006.

[10] S.S. Lakshmi and S.C. Myers, "Testing static tradeoff against pecking order models of capital structure1, "Journal of financial economics, vol.51(2), pp. 219-244, 1999.

[11] The China Foundation Center (CFC): China foundation transparency index (2010-2015). Available at http://ftien.foundationcenter.org.cn/, last accessed on May 23th, 2018.

[12] M.J. Flannery and K.P. Rangan, "Partial adjustment toward target capital structures, "Journal of financial economics, vol. 79(3), pp. 469506, 2006.

[13] A. Manuel and S. Bond, "Some tests of specification for panel data: Monte Carlo evidence and an application to employment equations," The review of economic studies, vol. 58(2), pp. 277-297, 1991.

[14] L. Nie, H.K. Liu, and W. Cheng, "Exploring factors that influence voluntary disclosure by chinese foundations," VOLUNTAS: International Journal of Voluntary and Nonprofit Organizations, vol. 27(5), pp. 2374-2400, 2016. 